\title{
Study Legal Sponsor Primary Indicator
}

National Cancer Institute

\section{Source}

National Cancer Institute. Study Legal Sponsor Primary Indicator. NCI Thesaurus. Code C94089.

Specifies whether this is the main or principal study legal sponsor. 